\title{
Does plant root architecture respond to potassium under water stress? A case from rice seedling root responses
}

\author{
Dipika S. Patel ${ }^{1}$, Bardhan Kirti ${ }^{2}$,*, P. Patel Dhiraji ${ }^{2}$, Parekh Vipulkumar ${ }^{2}$, \\ Jena Suchismita $^{2}$, V. Narwade Ajay ${ }^{1}$ and N. Chhatrola Harshadkumar ${ }^{2}$ \\ ${ }^{1}$ N.M. College of Agriculture, Navsari Agricultural University, Navsari 396 450, India \\ ${ }^{2}$ ASPEE College of Horticulture and Forestry, Navsari Agricultural University, Navsari 396 450, India
}

In plants, roots sense the availability of potassium and water. This study examined the influence of potassium availability on root architecture and above-ground growth under water-deficit condition. We found that the growth of rice seedlings was further reduced by low potassium under water stress. We noted considerable reduction in the root projected area, maximum width and width-to-depth ratio. Furthermore, high potassium supply helped in sustaining the root top and bottom angles and prevented root steepness under mild water stress. However, high potassium availability did not result in better seedling growth. Root steepness was more influenced by water than potassium levels under severe water stress.

Keywords: Drought, Oryza sativa L., potassium, root plasticity.

DEPENDING on the growing conditions, major factors that decide rice yields under drought are thickness, density, depth and distribution of the roots ${ }^{1}$. Furthermore, changes that occur in the early stage in the root angle, which contribute in the development of deep root systems, play a key role in drought tolerance of rice $^{2}$. A cross-talk may occur between signalling underlying sensing of water and nutrients by the roots, and in response to the availability of water and nutrients, root signals can regulate the growth of shoots ${ }^{3}$. Potassium (K) fertilizers are commonly applied to alleviate the adverse effects of water stress on many crops, including rice ${ }^{4,5}$. High $\mathrm{K}$ availability can cause an increase in the root diameter and dry matter ${ }^{6}$. Hormonal mechanisms are responsible for the effects exerted by $\mathrm{K}$ on the roots ${ }^{7}$. $\mathrm{K}$ also plays key roles in maintaining cell-water status ${ }^{8}$, stomatal openingclosing $^{9}$ and neutralizing reactive oxygen species ${ }^{10}$. In addition, during moisture stress, $\mathrm{K}$ might affect the spatial distribution of roots, termed as root architecture. However, because most previous studies have focused on root growth ${ }^{11}$ or have been conducted in the absence of

*For correspondence. (e-mail: kirtivardhan@nau.in) water stress ${ }^{6}$, the effect of $\mathrm{K}$ on the spatial distribution of roots under moisture stress remains unclear. Moreover, although the effect of water deficit on the roots of rice was studied earlier ${ }^{12}$, the collaborative influence of the availability of water and nutrients remains unclear. Therefore, the present study aims to examine the interactive effects of $\mathrm{K}$ and water availability on root architecture and rice seedling growth.

\section{Materials and methods}

Rice (Oryza sativa L.) variety NAUR-1, adapted to upland and lowland cultivation was used. Between 2017 and 2018, we conducted randomized, factorial-design experiments with three replicates in a naturally ventilated polyhouse at Navsari Agricultural University $\left(20.9248^{\circ} \mathrm{N}\right.$, $72.9079^{\circ} \mathrm{E}$ ). We pre-soaked rice seeds in deionized water for $24 \mathrm{~h}$, with five seeds being sown in each semitransparent polythene bag $(32 \times 20.5 \mathrm{~cm})$ containing $1.2 \mathrm{~kg}$ of a homogeneous mixture of sand and perlite (ratio of $2: 1,800+400 \mathrm{~g}$ ). Post emergence of shoots, we retained only two seedlings in each bag.

We examined three levels of water stresses: no water stress (NWS; field capacity (FC) of 100\%), mild water stress (MWS; FC of 60\%), and severe water stress (SWS; FC of $40 \%$ ). We used the gravimetric method to estimate FC. We used four water-saturated bags which had their tops covered to prevent evaporative loss, and kept them overnight to drain excess water. The following formula was used to calculate the amount of water retained at 100\% FC: ((weight of saturated media - weight of ovendried media)/weight of oven-dried media) $\times 100$. The medium was oven-dried at $105 \pm 1^{\circ} \mathrm{C}$ overnight to obtain a constant weight. Day-to-day evapotranspiration loss was recorded by weighing the four water-saturated bags daily and determining the difference in their weights at $100 \%$ FC. All the bags were initially replenished daily up to $100 \%$ FC using the unmodified Yoshida solution ${ }^{13}$ until the emergence of seedlings. Subsequently, we used the modified Yoshida solution to apply water stress (Figures $1 a$ and $b$ and 2). 
(a)

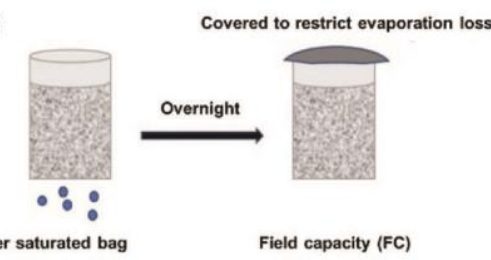

(b)

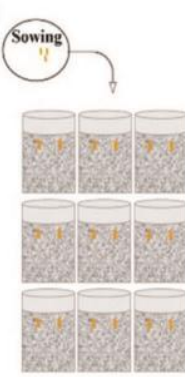

NWS $(100 \%$ FC)

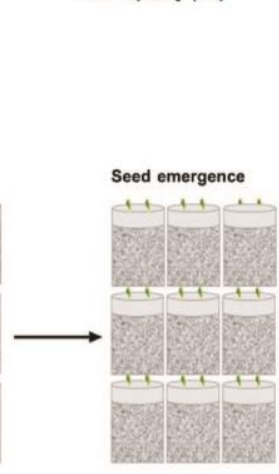

NWS (100\% FC)

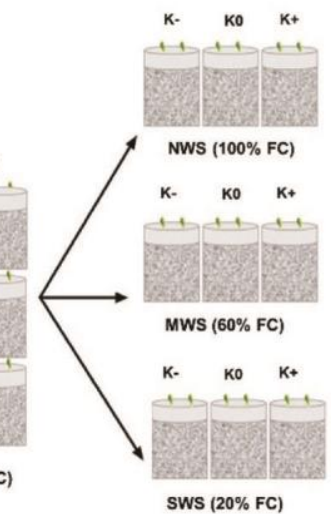

(c)
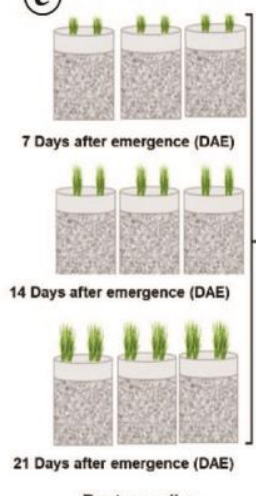

Root sampling
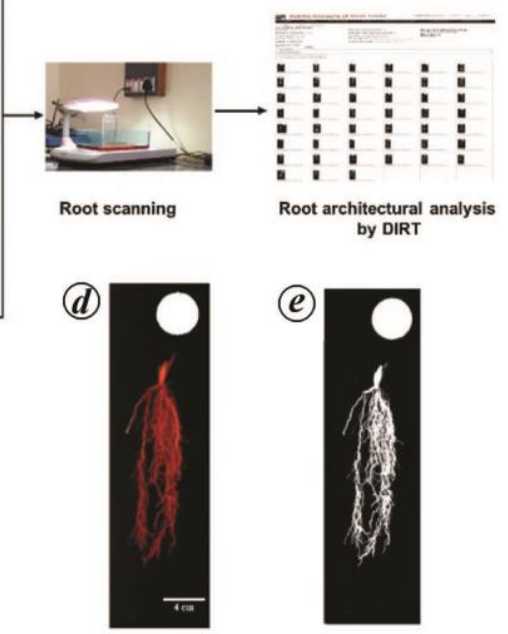

Figure 1. Schematic overview of the experiment: $\boldsymbol{a}$, estimation of field capacity; $\boldsymbol{b}$, treatment imposition; $\boldsymbol{c}$, analysis of root architecture. (Inset); $\boldsymbol{d}$, scanned root image; $\boldsymbol{e}$, masked root image.

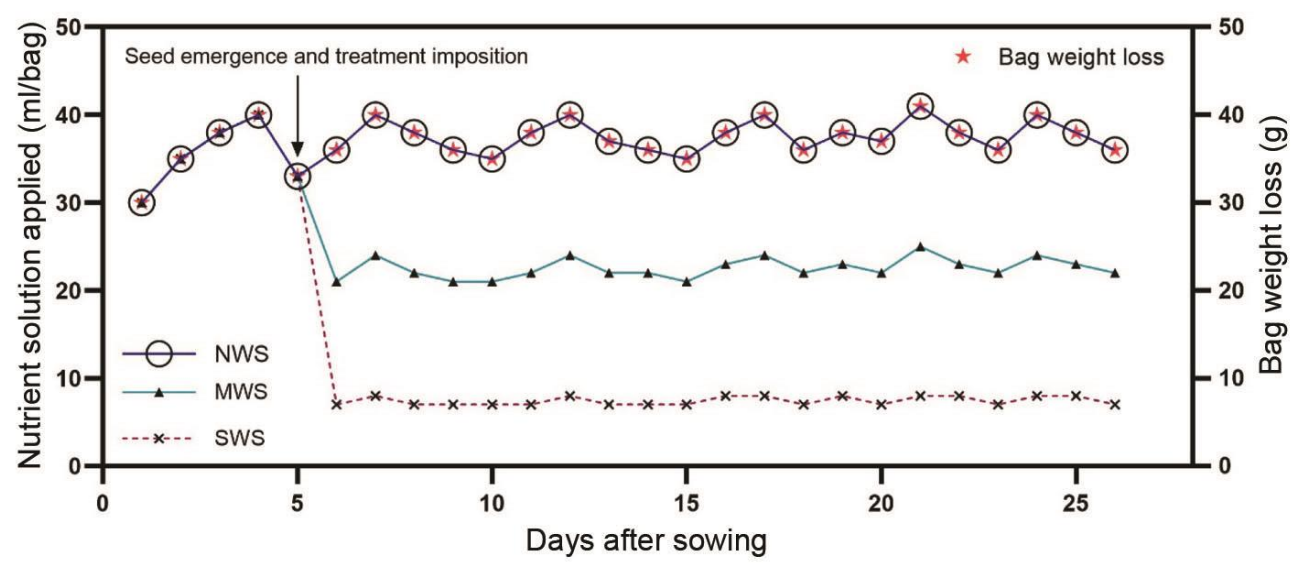

Figure 2. Day-by-day weight loss of bag ( $\mathrm{g}$ ) and amount of modified Yoshida solution applied ( $\mathrm{ml} / \mathrm{bag})$ in different water stress treatments.

We modified the Yoshida solution to develop three treatments of $\mathrm{K}: \mathrm{K}-$ (Yoshida solution containing 50\% low K, 20 ppm K, $35.7 \mathrm{~g} / \mathrm{l} \mathrm{K}_{2} \mathrm{SO}_{4}$ ), $\mathrm{K} 0$ (Yoshida solution containing optimal K, 40 ppm K, $71.4 \mathrm{~g} / \mathrm{K}_{2} \mathrm{SO}_{4}$ ), and $\mathrm{K}+$ (Yoshida solution containing 50\% high $\mathrm{K}, 60 \mathrm{ppm} \mathrm{K}$, $107.1 \mathrm{~g} / \mathrm{K}_{2} \mathrm{SO}_{4}$ ). Besides maintaining all other nutrient concentrations unchanged, sulphur concentration was adjusted by the amount of $\mathrm{H}_{2} \mathrm{SO}_{4}$ (specific gravity: 1.84, purity: $98 \%$ ) according to $\mathrm{K}_{2} \mathrm{SO}_{4}$ used in the treatments $\left(50 \mathrm{ml} / 1 \mathrm{H}_{2} \mathrm{SO}_{4}\right.$ in $\mathrm{K} 0,61.14 \mathrm{ml} / \mathrm{l}$ in $\mathrm{K}-$, and $38.85 \mathrm{ml} / \mathrm{l}$ in $\mathrm{K}+$ ). $\mathrm{pH}$ of the solution was adjusted to 5.5 before application.

We examined 405 root samples that represented the root system of five seedlings in each treatment at threetime intervals (7, 14 and 21 days after emergence (DAE)). Before scanning, the roots were placed under water in a scanner acrylic tray $\left(23.1 \times 15.5 \times 7 \mathrm{~cm}^{3}\right)$ for $45 \mathrm{~min}$ and then stained with a natural red dye $(0.25 \mathrm{~g} / \mathrm{l})$ to optimize the contrast and decrease the diffraction of scanner light from the roots. Root images were taken using a scanner (HP Scanjet G2410) at a resolution of 600 dpi. A $40 \mathrm{~mm}$ diameter circular scale marker placed under the scanner tray and all the images were captured with the scale marker (Figure $1 c$ ). To calculate root dry weight, we used the root samples of $21 \mathrm{DAE}$. We kept these samples in a hot-air oven at $65^{\circ} \pm 1^{\circ} \mathrm{C}$ overnight till a constant weight was achieved.

We computed the root architecture features through digital imaging of root traits (DIRT; figure 3$)^{14}$. All scanned images were adjusted at a masking threshold of 3 before computation (Figure $1 d$ and $e$ ). We converted DIRT results in pixels to metric units, except for the 


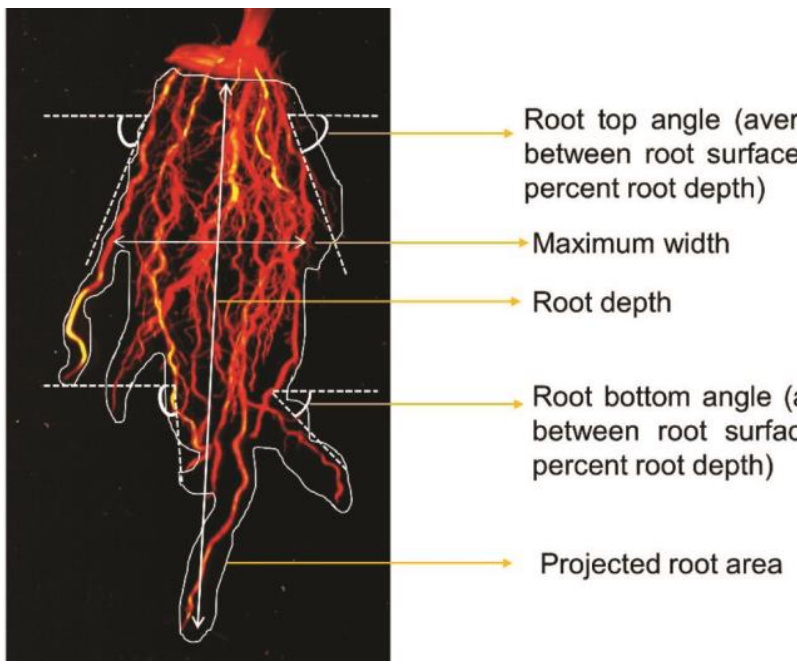

Figure 3. Rice seedling root architecture features studied.
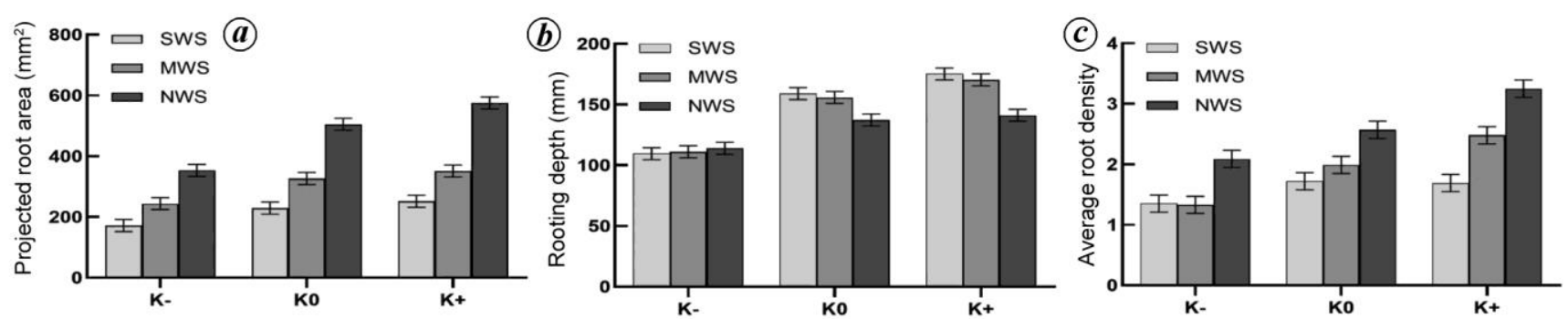

Figure 4. $\boldsymbol{a}$, Rice root projected root area; $\boldsymbol{b}$, root depth; $\boldsymbol{c}$, average root density at 21 DAE (days after emergence). NWS (no water stress), MWS (mild water stress) and SWS (severe water stress), K- (low potassium), K0 (optimum potassium), K+ (high potassium; mean \pm SEm).

average root density (which is the ratio of foreground to background pixels within the root shape) using the following formula

$$
\text { Calibration factor }=\frac{\text { Scale marker diameter }}{\text { Circle ratio (pixels) }} \text {. }
$$

The circle ratio (pixels) was computed by the DIRT platform.

$$
\begin{aligned}
& \text { Root depth }(\mathrm{mm})=\text { Length }(\text { pixels }) \times \text { calibration factor. } \\
& \begin{aligned}
\text { Maximum width }(\mathrm{mm})= & \text { Maximum width (pixels }) \\
& \times \text { calibration factor. }
\end{aligned}
\end{aligned}
$$

Projected root area $\left(\mathrm{mm}^{2}\right)=$ Area (pixels)

$$
\times \text { calibration } \text { factor }^{2} \text {. }
$$

At 21 DAE, we measured the length $(\mathrm{cm})$ and dry weight (g) of shoots of the same seedlings from each treatment that were sampled for root imaging. Analysis of variance was used to estimate treatment effects and we considered differences between mean values to be statistically significant if $p \geq 0.05$ (Table 1$)^{15}$.

\section{Results}

\section{Vertical features of root architecture}

We found that the projected root area (PRA), reduced with an increase in water stress, and a low $\mathrm{K}$ level caused a larger decrease in PRA (Figure $4 a$ ). A reduction of $51 \%$ and $66 \%$ was observed in PRA under MWS and SWS respectively, with a low $\mathrm{K}$ supply $(\mathrm{K}-)$ when compared with NWS seedlings grown with optimal K (K0). In addition, a $25 \%$ decrease in PRA was noted due to low $\mathrm{K}$ supply under the water stress treatments ( $\mathrm{K}-\mathrm{MWS}$ and $\mathrm{K}$ - SWS) compared with that under optimal K level. We found no significant effect of high $\mathrm{K}$ level $(\mathrm{K}+)$ under MWS and SWS treatments on root area compared to MWS and SWS treatments with optimum K supply.

Although seedling root depth (RD), increased under water stress, it decreased by up to $28.7 \%$ and $31.1 \%$ under MWS and SWS respectively, at low K level when compared with MWS and SWS at optimal K level (Figure $4 b$ ). However, in contrast to low $\mathrm{K}$ level, a high $\mathrm{K}$ level increased RD by $9.3 \%$ and $10 \%$ in MWS and SWS over optimum K level respectively. Moreover, the influence of high $\mathrm{K}$ on RD under the absence of water stress was not strong. 
We observed that the average root density decreased with increase in water stress (Figure $4 c$ ). Compared with an optimal K level under MWS, a low K level under MWS reduced root density by $33 \%$. However, the root density values from seedlings grown at a high $\mathrm{K}$ level under MWS were statistically equal to those obtained with an optimal K level under NWS. We did not find any significant difference in root density between SWS with a low or high K levels and SWS with optimum K level.

\section{Horizontal features of root architecture}

We observed that the maximum width (MW) of the roots reduced with an increase in water deficit (Figure $5 a$ ). The root width substantially decreased under low $\mathrm{K}$ level. Compared with MWS and SWS with optimal K supply, a reduction of $41 \%$ and $43 \%$ in root width was noted under MWS and SWS respectively, with low $\mathrm{K}$ availability.

Table 1. Summary of analysis of variance for water stress (WS), potassium $(\mathrm{K})$ and their interactions $(\mathrm{WS} \times \mathrm{K})$ on root architecture and seedling growth

\begin{tabular}{|c|c|c|c|}
\hline \multirow[b]{2}{*}{ Parameters ${ }^{\#}$} & \multicolumn{3}{|c|}{$P$ values } \\
\hline & WS & $\mathrm{K}$ & $\mathrm{WS} \times \mathrm{K}$ \\
\hline \multicolumn{4}{|c|}{ Projected root area $\left(\mathrm{mm}^{2}\right)$ at } \\
\hline $7 \mathrm{DAE}$ & $*$ & $*$ & $\mathrm{~ns}$ \\
\hline $14 \mathrm{DAE}$ & $*$ & $*$ & ns \\
\hline $21 \mathrm{DAE}$ & $*$ & $*$ & $*$ \\
\hline \multicolumn{4}{|l|}{ Root depth (mm) at } \\
\hline $7 \mathrm{DAE}$ & $*$ & $*$ & ns \\
\hline $14 \mathrm{DAE}$ & $*$ & $*$ & $*$ \\
\hline $21 \mathrm{DAE}$ & $*$ & $*$ & $*$ \\
\hline \multicolumn{4}{|c|}{ Maximum width $(\mathrm{mm})$ at } \\
\hline $7 \mathrm{DAE}$ & $*$ & $*$ & $\mathrm{~ns}$ \\
\hline $14 \mathrm{DAE}$ & $*$ & $*$ & $\mathrm{~ns}$ \\
\hline $21 \mathrm{DAE}$ & $*$ & $*$ & $*$ \\
\hline \multicolumn{4}{|l|}{ Average root density at } \\
\hline $7 \mathrm{DAE}$ & $*$ & $*$ & $\mathrm{~ns}$ \\
\hline $14 \mathrm{DAE}$ & $*$ & $*$ & $*$ \\
\hline $21 \mathrm{DAE}$ & $*$ & $*$ & $*$ \\
\hline \multicolumn{4}{|c|}{ Maximum width-to-depth ratio at } \\
\hline $7 \mathrm{DAE}$ & $*$ & $*$ & $*$ \\
\hline $14 \mathrm{DAE}$ & $*$ & $*$ & $*$ \\
\hline $21 \mathrm{DAE}$ & * & $*$ & $\mathrm{~ns}$ \\
\hline \multicolumn{4}{|l|}{ Root top angle $\left(^{\circ}\right)$ at } \\
\hline $7 \mathrm{DAE}$ & $*$ & $*$ & ns \\
\hline $14 \mathrm{DAE}$ & $*$ & $*$ & $\mathrm{~ns}$ \\
\hline $21 \mathrm{DAE}$ & $*$ & $*$ & $*$ \\
\hline \multicolumn{4}{|c|}{ Root bottom angle $\left({ }^{\circ}\right)$ at } \\
\hline $7 \mathrm{DAE}$ & $*$ & $*$ & $\mathrm{~ns}$ \\
\hline $14 \mathrm{DAE}$ & $*$ & $*$ & ns \\
\hline $21 \mathrm{DAE}$ & $*$ & $*$ & $*$ \\
\hline Root dry weight (g) & $*$ & $*$ & * \\
\hline Shoot length (cm) & $*$ & $*$ & $*$ \\
\hline Shoot dry weight (g) & $*$ & $*$ & $*$ \\
\hline Total dry weight (g) & $*$ & $*$ & $*$ \\
\hline
\end{tabular}

"Root parameters of 7 and 14 DAE (days after emergence) are presented in the Supplementary Figures 1 and 2 and total dry weight (g) in Supplementary Figure 3. *Significant at $p \geq 0.05$, ns: not significant.
However, we found that seedlings supplied with high $\mathrm{K}$ under MWS and SWS showed $20 \%$ and $48 \%$ more wide roots respectively, against seedlings of MWS and SWS with optimal K supply.

Water stress caused a reduction in the MW/RD ratio (Figure $5 b$ ). We observed that the MW/RD ratio increased by $6.5 \%$ at high $\mathrm{K}$ level, but decreased by $12.3 \%$ with low $\mathrm{K}$ supply compared with that under optimal $\mathrm{K}$ level for seedling under no water stress. Although $\mathrm{K}$ availability did not affect the MW/RD ratio at $21 \mathrm{DAE}$ under different water stress treatments, there was a significant interaction at 7 and 14 DAE (Supplementary Figure $2 a$ and $b$ ).

We observed the narrowest root top angle (RTA) under NWS and the widest SWS (Figure $5 c$ ). Compared with NWS, RTA increased by $6^{\circ}$ and $17.2^{\circ}$ under MWS and SWS respectively, with optimum K level. However, similar effects of different K levels on RTA were found under MSW. Rice seedlings that were exposed to SWS with a high K level exhibited narrower RTA (49.9 $)$ compared with those exposed to SWS with a low K supply $\left(61.9^{\circ}\right)$. However, RTA determined under SWS with high K level was similar to that under MWS with optimal K level $\left(46.0^{\circ}\right)$.

Water stress also increased the root bottom angle (RBA, Figure $5 d$ ). Compared with NWS $\left(55.0^{\circ}\right)$, RBA values were $63.7^{\circ}$ and $74.1^{\circ}$ under MWS and SWS respectively, with optimal $\mathrm{K}$ supply. Furthermore, rice seedlings demonstrated RBA values of $71.7^{\circ}$ and $79.4^{\circ}$ when treated with MWS and SWS respectively, with low $\mathrm{K}$ level. The values increased by $8^{\circ}$ and $5.3^{\circ}$ under MWS and SWS with optimal K supply respectively. These findings indicate that roots are more narrowly spread at the
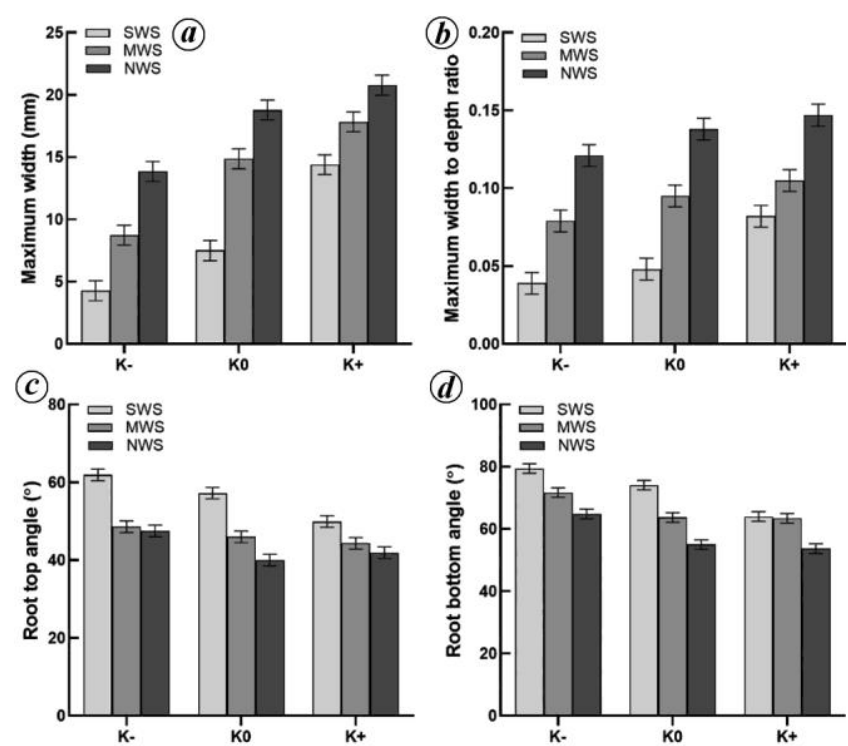

Figure 5. $\boldsymbol{a}$, Rice root maximum width; $\boldsymbol{b}$, maximum width-to-root depth ratio; $\boldsymbol{c}$, root top angle; $\boldsymbol{d}$, root bottom angle at 21 DAE (mean \pm SEm). 
bottom under water stress with low $\mathrm{K}$ availability. However, no difference in RBA was observed between seedlings grown with high K supply under MWS and those supplied with optimum K under MWS. Under SWS, high $\mathrm{K}$ supply reduced RBA by $10^{\circ}$ over optimal K level.

\section{Root dry weight}

We observed that root dry weight (RDW), decreased with increase in water stress (Figure 6b). Compared with RDW of seedlings grown under MWS and SWS with optimal K supply, a reduction of $31 \%$ and $49 \%$ was noted in RDW of rice seedlings grown under MWS and SWS at a low $\mathrm{K}$ level respectively. Also, compared with rice seedlings grown under SWS with optimum K level, an increase of $15.6 \%$ was observed in the RDW of rice seedlings grown under SWS at high K level. However, we did not find such an increase in seedlings treated with MWS.

\section{Seedling growth}

The shoot length of rice seedlings subjected to MWS and SWS with optimum K supply was $16 \%$ and $30 \%$, lower than that of seedlings under NWS respectively (Figure $6 a$ ). Furthermore, no significant difference in shoot length was observed between seedlings supplied with low and high K solution under NWS. However, we found that the shoot length of seedlings exposed to MWS and SWS at low $\mathrm{K}$ level was $21 \%$ and $24 \%$ lower respectively, than that of seedlings grown under MWS and SWS with optimum K. Furthermore, the supply of high K to rice seedlings exposed to MWS and SWS showed increased shoot length by $12.8 \%$ and $24.8 \%$ respectively, against to those grown under MWS and SWS with optimum K supply. The shoot dry weight of seedlings reduced with an increase in water stress (Figure $6 b$ ). This reduction was higher by $40 \%$ in rice seedlings exposed to MWS at low $\mathrm{K}$ level than those exposed to MWS at optimum K level. The shoot dry weight values were similar between seedlings subjected to MWS at high K level and those subjected to MWS at optimum K level. However, no significant difference in shoot dry weight values was observed between seedlings supplied with low and high $\mathrm{K}$ under SWS. The total dry weight values were similar between seedlings under MWS and SWS with high K level and those under MWS and SWS at optimum K level (Supplementary Figure 3). However, seedlings from MWS and SWS at low K level exhibited a significant decrease in total dry weight.

\section{Discussion}

Although the genetics of the rice variety regulates its root architecture, a broad variation of phenotypic plasticity is observed due to the availability of nutrients ${ }^{16}$ and water ${ }^{17}$, and this is crucial for the drought tolerance of rice ${ }^{12}$. In the present study, we found water and $\mathrm{K}$ availability both interact in regulating the root system of rice seedlings (Figures 7 and 8). We observed a decrease in PRA and average root density with an increase in water stress. This detrimental effect was more at a low K level; however, such reduction in PRA and average root density was not seen in seedlings exposed to MWS and SWS at optimum and high K levels. Similarly, a study reported that K increased the root surface area, volume and root tip number in tomato under atmospheric drought ${ }^{18}$. The strong effects of water deficit on these traits indicate that both $\mathrm{K}$ and water are limiting factors that may independently regulate these root traits. The translocation of sugar depends on $\mathrm{K}$ availability ${ }^{19}$ which triggers cell division ${ }^{20}$, whereas cell elongation depends on cell turgor ${ }^{21}$ and water content. The results of this study indicate that an optimum $\mathrm{K}$ level is crucial for the development of the root system because rice seedlings exposed to NWS with a low K level exhibited decreased root area compared with seedlings exposed to NWS with an optimum K level. This finding may be attributed to the loss of turgidity resulting from low water absorption ${ }^{21}$ and the sub-optimal levels of auxin in the root tip under low $\mathrm{K}$ availability ${ }^{22}$.

The horizontal and vertical elongation of the roots is responsible for the exploration of soil area and uptake of
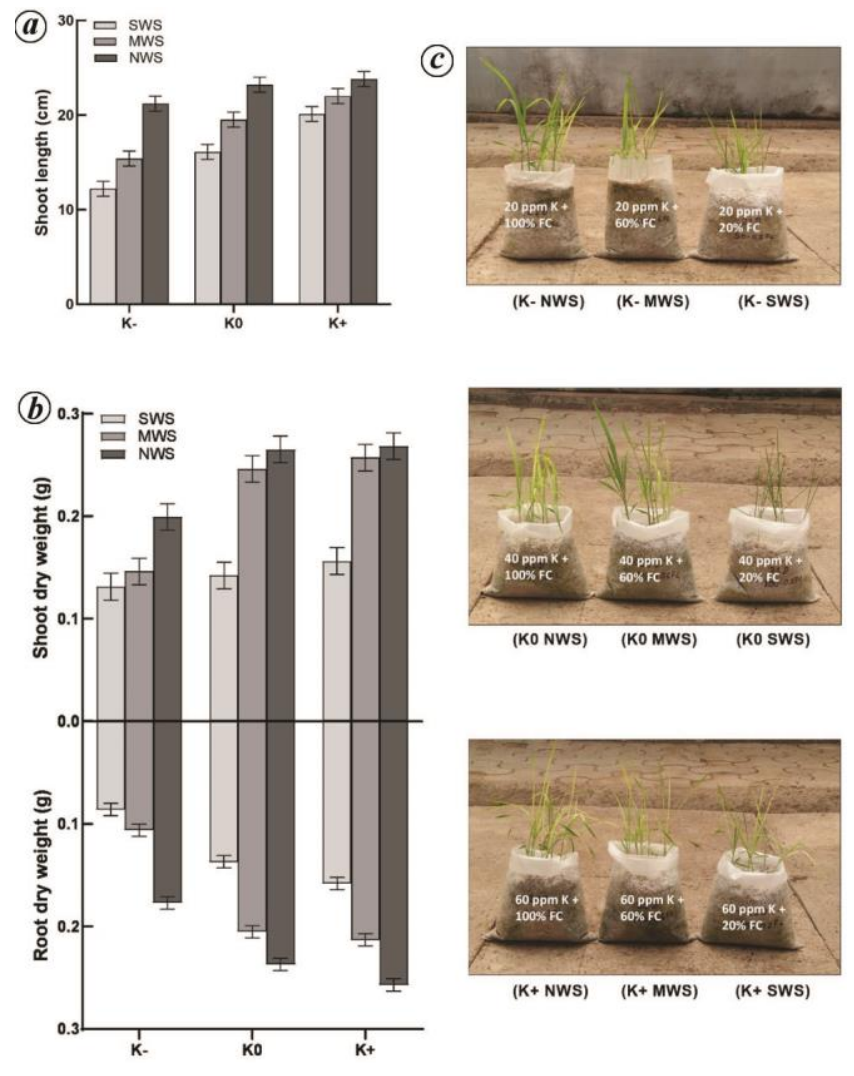

Figure 6. $\boldsymbol{a}$, Rice seedling shoot length; $\boldsymbol{b}$, shoot and root dry weight; $c$, seedlings growth at 21 DAE (mean \pm SEm). 


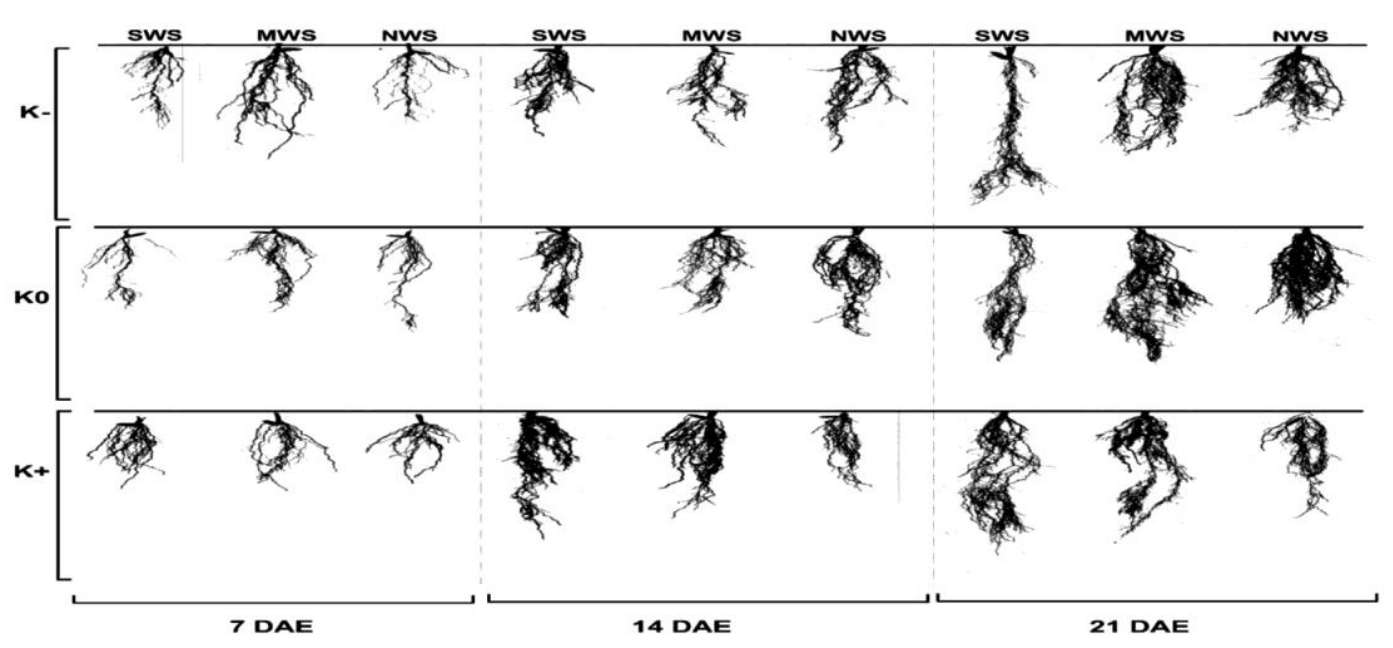

Figure 7. Rice root system architecture under SWS, MWS and NWS with K-, K0 and K+ at 7, 14 and 21 DAE.
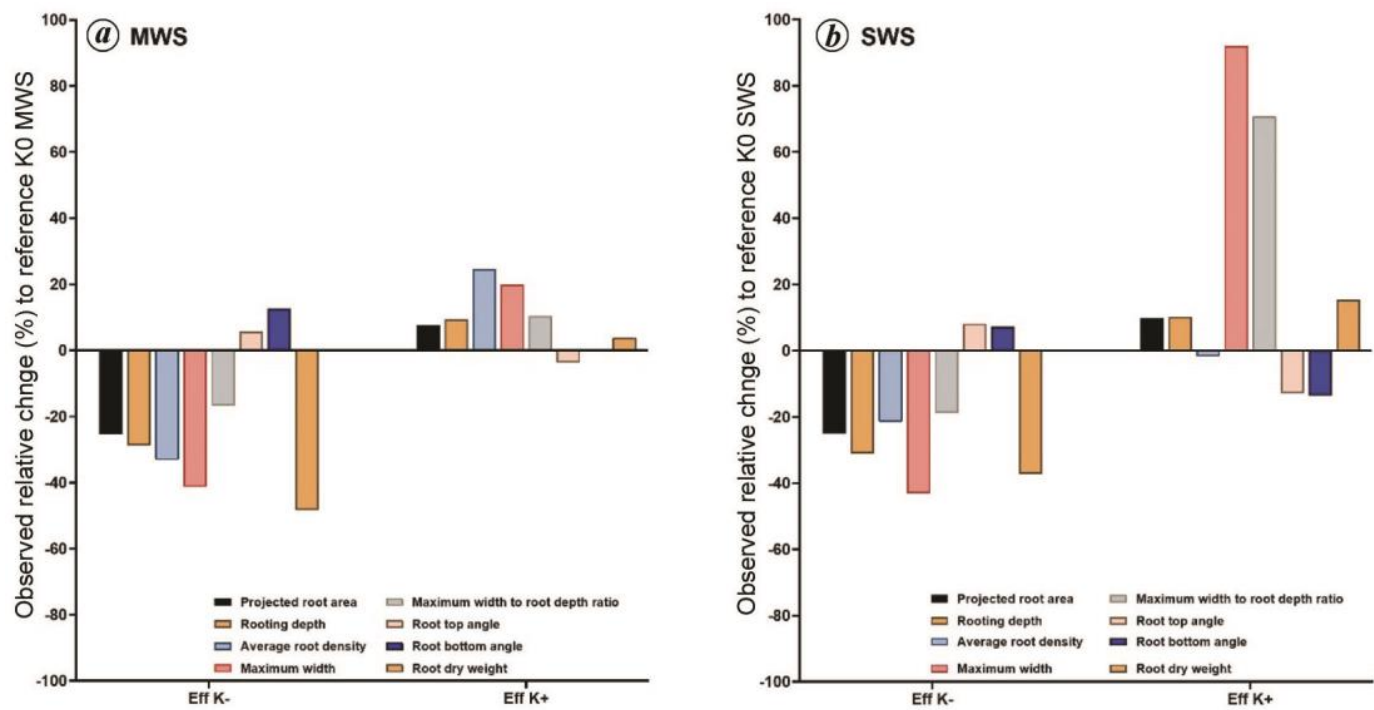

Figure 8. Observed relative changes (\%) in different rice seedling root features due to the effect of $\mathrm{K}-$ and $\mathrm{K}+$ under $(\boldsymbol{a})$ MWS and (b) SWS. Individual effect was calculated over K0 (optimum potassium) with the respective water stress.

soil resources. In the present study, we calculated the root depth, maximum width and ratio of maximum width to root depth to determine whether the roots expand preferentially in the horizontal or vertical direction. We found that the root depth increased and maximum width decreased with increase in water stress, resulting in a low $\mathrm{MW} / \mathrm{RD}$ ratio. This finding indicates that with increasing water deficit, the roots expand vertically rather than horizontally to reach the water source deep down in the soil, thus resulting in steeper root growth. However, with $\mathrm{K}$ sufficiency under water stress, the roots expanded horizontally, resulting in an increased root width and $\mathrm{MW} / \mathrm{RD}$ ratio. We also observed that roots exhibiting steep growth had wide root top and bottom angles under MWS and SWS, suggesting that the roots had lesser surface contact area with the surrounding medium. On farmlands, these characteristics can restrict the acquisition of water and nutrients efficiently from the soil. In this study, high $\mathrm{K}$ supply helped maintain the top and bottom angles in seedlings exposed to MWS. However, high K availability did not exert this positive effect in seedlings exposed to SWS. These results suggest that in addition to increasing the translocation of mineral nutrients in the xylem under water stress ${ }^{23}$, K fertilization maintains RTA and RBA, thus increasing the root-soil contact area and may play a key role to nutrient acquisition by reaching more soil areas. The synthesis, transport and signalling of auxin are the main factors involved in the development of rice roots ${ }^{24}$. An auxin-inducible DRO gene controls root depth. This gene regulates the root top angle, thus deciding the direction of root elongation ${ }^{2}$. However, the mechanisms through which $\mathrm{K}$ availability results in variations in root top and bottom angles remain unclear. However, $\mathrm{K}$ was found to affect auxin signalling and 
translocation in rice; the $\mathrm{K}$ transporter altered membranebound auxin efflux proteins ${ }^{25,26}$ and may change the root angle.

Water stress caused a reduction in seedling growth, and reduction in root dry weight, shoot dry weight, and seedling height was more with low $\mathrm{K}$ availability. However, high $\mathrm{K}$ level could ameliorate these effects and increase shoot length, shoot dry weight and root dry weight. The beneficial effects of a high $\mathrm{K}$ level were more pronounced in seedlings exposed to MWS. The application of high K under SWS did not increase total dry weight compared with optimum K level under SWS. These results are in agreement with that of a previous study ${ }^{27}$.

\section{Conclusion}

This study shows that the interaction of $\mathrm{K}$ and water stress influences the three-dimensional distribution of roots. This can be beneficial for exploring underground resources in order to promote the growth of rice seedlings above the ground under MWS depending upon K availability. The results emphasize the need to maintain $\mathrm{K}$ availability in soils under water stress. These findings provide insights into the role of $\mathrm{K}$ in drought tolerance through modification of root architecture. Additional studies should examine the degree to which root architecture is shaped by water and $\mathrm{K}$ availability in a broad genetic background.

1. Gowda, V. R. P., Henry, A., Yamauchi, A., Shashidhar, H. E. and Serraj, R., Root biology and genetic improvement for drought avoidance in rice. Field Crops Res., 2011, 122, 1-13.

2. Uga, Y., Sugimoto, K., Ogawa, S., Rane, J., Ishitani, M. and Hara, N., Control of root system architecture by DEEPER ROOTING 1 increases rice yield under drought conditions. Nature Genet., 2013, 45, 1097-1102.

3. Kudoyarova, G. R., Dodd, I. C., Veselov, D. S., Rothwell, S. A. and $\mathrm{Yu}$ Veselov, S., Common and specific responses to availability of mineral nutrients and water. J. Exp. Bot., 2015, 66, 2133-2144.

4. Grzebisz, W., Gransee, A., Szczepaniak, W. and Diatta, J., The effects of potassium fertilization on water-use efficiency in crop plants. J. Plant Nutr. Soil Sci., 2013, 176, 355-374.

5. Zain, N. A. M. and Ismail, M. R., Effects of potassium rates and types on growth, leaf gas exchange and biochemical changes in rice (Oryza sativa) planted under cyclic water stress. Agric. Water Manage., 2016, 164, 83-90.

6. Filho, A. C. A. C., Crusciol, C. A. C., Nascente, A. S., Mauad, M. and Garcia, R. A., Influence of potassium levels on root growth and nutrient uptake of upland rice cultivars. Rev. Caatinga, 2017, 30(1), 32-44.

7. Tatsumi, J., Endo, N. and Kono, Y., Root growth and partitioning of ${ }^{13} \mathrm{C}$-labelled photosynthate in the seminal root of corn seedlings as affected by light intensity. Jpn. J. Crop Sci., 1992, 61, 271-278.

8. Mengel, K. and Arneke, W. W., Effect of potassium on the water potential, the pressure potential, the osmotic potential and cell elongation in leaves of Phaseolus vulgaris. Physiol. Plant, 1982, 54, 402-408.
9. Benlloch-González, M., Arquero, O. J., Fournier, M., Barranco, D. and Benlloch, M., K+ starvation inhibits water-stress-induced stomatal closure. J. Plant Physiol., 2008, 165, 623-630.

10. Cakmak, I., The role of potassium in alleviating detrimental effects of abiotic stresses in plants. J. Plant Nutr. Soil Sci., 2005, 168, 521-530.

11. Jordan-Meille, L., Martineau, E., Bornot, Y., Lavres, J., Abreu Jr, H. C. and Domec, J. C., How does water-stressed corn respond to potassium nutrition? A shoot-root scale approach study under controlled conditions. Agriculture, 2018, 8, 180.

12. Kano-Nakata, M. et al., Functional roles of the plasticity of root system development in biomass production and water uptake under rainfed lowland conditions. Field Crops Res., 2013, 144, 288-296.

13. Yoshida, S., Forno, D. A., Cock, J. H. and Gomez, K. A., Laboratory Manual for Physiological Studies of Rice, The International Rice Research Institute, Philippines, 1976, 2nd edn.

14. Das, A. et al., Digital imaging of root traits (DIRT): a high throughput computing and collaboration platform for field-based root phenomics. Plant Methods, 2015, 11, 51.

15. Gomez, K. A. and Gomez, A. A., Statistical Procedures for Agricultural Research, John Wiley, New York, USA, 1984, 2nd edn.

16. Shahzad, Z. and Amtmann, A., Food for thought: how nutrients regulate root system architecture. Curr. Opin. Plant Biol., 2017, 39, 80-87.

17. Giehl, R. F. H. and Von Wiren, N., Hydropatterning - how roots test the waters. Science, 2018, 362, 1358-1359.

18. Zhang, J., Jiao, X., Du, Q., Song, X., Ding, J. and Li, J., Effects of vapor pressure deficit and potassium supply on root morphology, potassium uptake, and biomass allocation of tomato seedlings. J. Plant Growth Regul., 2020; https://doi.org/10.1007/s00344-02010115-2.

19. Martineau, E., Domec, J. C., Bosc, A., Dannoura, M., Gibon, Y., Bernard, C. and Jordan-Meille, L., The role of potassium on maize leaf carbon exportation under drought condition. Acta Physiol. Plant, 2017, 39, 219.

20. Wang, L. and Ruan, Y. L., Regulation of cell division and expansion by sugar and auxin signaling. Frontiers Plant Sci., 2013, 4, 163.

21. Gerardeaux, E., Jordan-Meille, L., Constantin, J., Pellerin, S. and Dingkuhn, M., Changes in plant morphology and dry matter partitioning caused by potassium deficiency in Gossypium hirsutum (L.). Environ. Exp. Bot., 2010, 67, 451-459.

22. Song, W. et al., Potassium deficiency inhibits lateral root development in tobacco seedlings by changing auxin distribution. Plant Soil, 2015, 396(1/2), 163-173.

23. Hasanuzzaman, M. et al., Potassium: a vital regulator of plant responses and tolerance to abiotic stresses. Agronomy, 2018, 8, 31 .

24. Wang, Y., Zhang, T., Wang, R. and Zhao, Y., Recent advances in auxin research in rice and their implications for crop improvement. J. Exp. Bot., 2018, 69, 255-263.

25. Yang, T. et al., The potassium transporter OsHAK5 alters rice architecture via ATP-dependent transmembrane auxin fluxes. Plant Commun., 2020, 1, 100052.

26. Sustr, M., Soukup, A. and Tylova, E., Potassium in root growth and development. Plants, 2019, 8, 435.

27. Zain, N. A. and Ismail, M. R., Effects of potassium rates and types on growth, leaf gas exchange and biochemical changes in rice (Oryza sativa) planted under cyclic water stress. Agric. Water Manage., 2016, 164, 83-90.

Received 22 January 2020; revised accepted 4 December 2020

doi: $10.18520 / \mathrm{cs} / \mathrm{v} 120 / \mathrm{i} 6 / 1050-1056$ 